\title{
The Intelligent Information System of Estimation of Lands of Agricultural Purpose
}

Ksenia V. Raevich, Yurii A. Maglinets and Gennady M. Tsibul'skii*

Siberian Federal University 79 Svobodny, Krasnoyarsk, 660041, Russia

Received 00.06.2016, received in revised form 00.08.2016, accepted 00.11.2016

Intelligent information system has been developed, which allows to solve problems of ranging agricultural land on the basis of knowledge of the operating characteristics of their data and GIS agricultural monitoring. It was formulated model estimating agro-economic potential of the land. Architecture of the system was examined.

Keywords: geographic information systems, support of a decision making, agricultural monitoring, geospatial data, estimation of lands of agricultural purpose.

\section{Интеллектуальная информационная система оценивания земель \\ сельскохозяйственного назначения}

\author{
К.В. Раевич, Ю.А. Маглинец, Г.М. Цибульский \\ Сибирский федеральный университет \\ Россия, 660041, Красноярск, пр. Свободный, 79
}

\begin{abstract}
Разработана интеллектуальная информационная система, позволяющая решать задачи ранжирования сельскохозяйственных земель на основе оперирования знаниями об их характеристиках и данными ГИС агромониторинга. Сформулирована модель оценивания агроэкономического потенииала земель. Рассмотрена архитектура системы.
\end{abstract}

Ключевые слова: геоинформачионные системы, поддержка принятия решений, агромониторинг, геопространственные данные, оиенивание земель сельскохозяйственного назначения.

(c) Siberian Federal University. All rights reserved

* Corresponding author E-mail address: kshatrova@sfu-kras.ru 


\section{Введение}

Задача оценки состояния земельных ресурсов, используемых в сельскохозяйственном производстве, носит междисциплинарный характер. Она возникает при решении вопросов организации управления АПК, в растениеводстве, землеустройстве, экономике, кадастровом учете и др. Земля как объект оценивания представляет собой сложную иерархическую многофакторную систему.

В начальном приближении все задачи оценивания можно разделить на две категории. В первом случае целью является получение интегральной оценки текущего состояния земельного участка, основанной на натурных измерениях, знаний о предыстории его использования, состояния его инфраструктуры и других значимых факторов. В зависимости от особенностей задачи результатом ее решения может быть оценка рыночной либо кадастровой стоимости, присвоение балла бонитета, ранга в системе сравнительного анализа земель и др. Во втором случае цель - получение частной оперативной оценки состояния растительного покрова либо хода агротехнических мероприятий. Такая необходимость возникает в задачах мониторинга, результаты используются для принятия управленческих решений, контроля эффективности мероприятий, расходования бюджетных средств, прогнозирования урожайности, формирования отчетности и др.

Анализ литературы [1-8] показывает высокую вариабельность задач оценивания ЗСХН и методов их решения. Так, согласно [1] определяющими факторами, влияющими на рыночную стоимость сельскохозяйственных угодий, являются: природноклиматические условия; вид сельскохозяйственных угодий; плодородие сельскохозяйственных угодий; уровень урожайности; место расположения земельного участка относительно рынков сбыта сельскохозяйственной продукции; производственная и социальная инфраструктура предприятия. Ценовая политика разнится в зависимости от категории земли. Поэтому, чтобы оценить рыночную стоимость земель сельскохозяйственного назначения, необходимо установить специфику использования земельного участка: вид использования земли (пашня, сенокос, залежные земли, многолетние насаждения т.д.), а также степень плодородия почвы. В [2] представлена альтернативная система факторов для территорий с нестабильной структурой сельскохозяйственного землепользования. Основой ранжирования земель служит их классификация по параметрам, связанным с оптимальным типом землепользования, продуцирующей способности земель, оцениваемой по данным сенсора MODIS, а также диапазона минимальных расстояний до открытой воды.

В целом можно отметить наличие в научной литературе по данному вопросу множества частично перекрывающихся систем классификации параметров земель, существенных при оценивании. Основой для непротиворечивого представления информации, полученной из разнородных источников, служит онтологический подход. При построении систем оперирования геопространственной информацией обсуждается понятие геоонтологии [9-10]. В настоящей статье предлагается способ формирования библиотеки схем решения задач оценивания в диалоге с конечным пользователем, базирующейся на системе упорядочения знаний о землях сельскохозяйственного назначения как об объектах оценивания в форме онтологии, инвариантной к конкретной решаемой задаче. 


\section{Онтология оценивания ЗСХН}

Подходы к построению онтологии оценивания агроэкономического потенциала земель развиты в работах $[8,11]$. При построении онтологии под объектом оценивания (OO) будем понимать пространственно локализованный участок земной поверхности, находящийся в сельскохозяйственном обороте в настоящее время, в прошлые временные периоды либо потенциально рассматриваемый в качестве такового. Согласно российскому законодательству в данную категорию попадают земли сельскохозяйственного назначения (ЗСХН). Кроме того, в качестве объекта оценивания могут рассматриваться и другие категории земель, относительно которых существуют планы перевода в данную категорию после выполнения мелиоративных мероприятий, например земли промышленности, лесного фонда.

Онтология оценивания задается четверкой

$$
O=<K, T, E, M>\text {, }
$$

где $K$ - таксономия признаков оценивания; $T$ - множество решаемых задач; $E$ - множество метрик оценивания признаков; $M$ - множество первичных метрик, позволяющих вычислить численное значение признака в натуральном выражении.

В основе рассматриваемой онтологической модели лежит таксономия $K$ оценивания агроэкономического потенциала земель (ТОАПЗ)

$$
K=\langle N, R>
$$

где $N=\left\{n_{i}\right\}$ - множество классов таксономии - признаков объекта оценивания, $R \subset N \times \mathbf{x}_{N}$-отношение порядка на $N$. Корневая вершина таксономического дерева соответствует искомой интегральной характеристике объекта оценивания. В рассматриваемой версии таксономии верхний уровень классификации задает шесть классов признаков, исчерпывающим образом описывающих предметную область (рис. 1).

Далее при нисходящем построении таксономии оценивания сформированы поддеревья различной глубины, вершины которых могут быть классифицированы следующим образом: абстрактные вершины; означиваемые вершины. Абстрактные вершины - вершины, исполь-

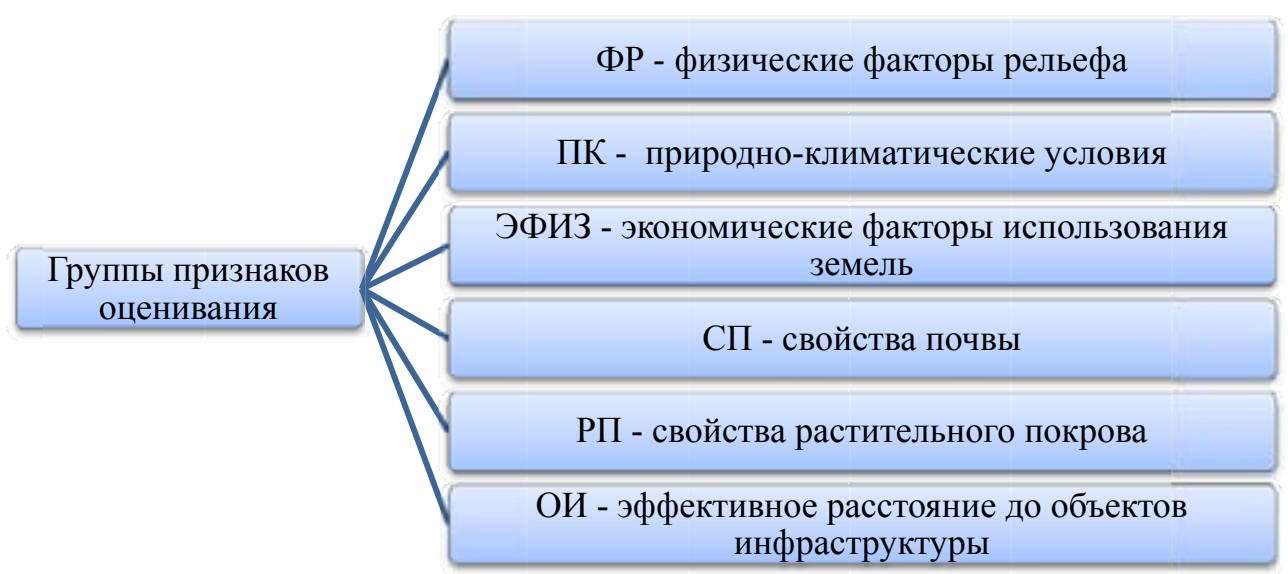

Рис. 1. Структура верхнего уровня таксономии признаков оценивания ЗСХН 
зуемые при классификации и навигации по ТОАПЗ, для которых не предусмотрена процедура вычисления оценки. Означиваемые вершины - соответственно, вершины, для которых существует формально определенная процедура, позволяющая сопоставлять ОО-значение соответствующего признака. Все листовые вершины дерева таксономии являются означиваемыми. Означивание для листовой вершины - это процедура расчета оценки, основанная на измерении натурных параметров ОО. Для узлов ветвления в общем случае существует два способа означивания: 1) способ, аналогичный способу, определенному для листовой вершины; 2) способ, основанный на агрегации параметров, ранее вычисленных для дочерних вершин данного узла. Далее по тексту будем называть их соответственно означиванием на основе измерения, означиванием на основе агрегаџии. Такой механизм позволяет осуществлять оценивание ОО с разной степенью точности, в зависимости от особенностей решаемой задачи, стоимости (в широком смысле) получения данных и т.п.

Для измерения натурных параметров в онтологии используются первичные метрики, представленные в (1) множеством $M$. Отдельная метрика $m_{i} \in M$ есть функциональное свойство, сопоставленное соответствующему узлу $n_{j} \in N$, для которого установлены интервал допустимых значений и единица измерения.

Для означивания на основе измерений в онтологии имеется множество метрик оценивания $E_{m} \subset E$, также заданных в форме функциональных свойств $e_{j} \in E_{m}$, сопоставленных узлу $n_{j}$. Для $e_{j}$ определена функциональная зависимость, позволяющая вычислить численную оценку признака $n_{i}$ на основе значения первичной метрики $m_{j}$. Результирующая комбинация $\left\langle n_{i}, m_{j}, e_{j}\right\rangle$ $\in N \times M \times E_{m}$ задает экземпляр соответствующего тернарного отношения, однозначно определяющий правила означивания на основе измерения.

Для означивания на основе агрегации в онтологии представлено множество метрик оценивания $E_{a} \subset E ; E=E_{m} \cup E_{a}$; $E_{m} \cap E_{a}=\varnothing$. Отдельная метрика $e_{i}$ описывается:

1) функциональным свойством, соотносящим $e_{i}$ оцениваемому признаку $n_{j}$;

2) взвешенным деревом агрегации глубины 1 с корневой вершиной $e_{i}$ и множеством вершин - метрик оценивания, инцидентных элементам подмножества $X$ множества дочерних вершин $Y$ вершины $n_{j}$ в таксономии оценивания. Веса дуги дерева характеризуют степень влияния оценки соответствующей дочерней вершины на оценку корневой вершины;

3) вычислительной процедурой, позволяющей вычислить оценку $e_{i}$ для признака $n_{j}$ на основе агрегации значений оценок узлов $x_{l} \in X$ и весов дуг дерева агрегации.

Рассмотренные выше компоненты онтологии задают основу для построения системы решения задач оценивания. Решаемые задачи $t_{j}$ задают множество $T$ задач, представленных в ТОАПЗ. Структура описания отдельной задачи $t_{i}$ аналогична структуре ТОАПЗ:

$$
t_{i}=<K_{i}, E_{i}, M_{i}>
$$

где $K_{i} \subset K$ - подграф таксономии оценивания, соответствующий решаемой задаче; $M_{i} \subset$ $M$ - множество первичных метрик, релевантных задаче оценивания; $E_{i}$ - множество метрик оценивания. В качестве $E_{i}$ может выступать подмножество $E$. Альтернативный вариант построение $E_{i}$ на основе модифицированного подмножества $E$. Модификация осуществляется с целью подбора более точных способов оценивания, соответствующих решаемой задаче. 


\section{Архитектура интеллектуальной информационной системы}

Основные компоненты системы показаны на рис. 2. База знаний содержит репозиторий онтологий, поддерживает средства обеспечения целостности информации, управления версиями и изменениями. Редактор базы знаний позволяет эксперту, ответственному за содержание онтологии, осуществлять диалоговые операции по созданию новой онтологии (версии онтологии) и ее редактированию в части описания таксономии, метрик измерения натурных параметров ОО и вычислительных соотношений. Генератор схемы решения задачи (СР3) позволяет эксперту, ответственному за представление задачи, создавать и поддерживать модель описания задачи в рамках определенной версии онтологии, а также осуществлять операции по миграции описания задачи в обновленные версии онтологии. При создании и модификации онтологии возникает процедура описания вычислительных соотношений для метрик оценивания. Данная процедура базируется на использовании редактора формул, который входит как компонента в редактор базы знаний и генератор схемы решения задачи. Помимо базовых математических операций генератор формул содержит возможность формирования таблично заданных функций.

Редактор геопространственных данных (ГПД) служит для подготовки и оперирования геопространственным описанием экземпляра решаемой задачи. При создании пустого экземпляра решаемой задачи модуль выгрузки СР3 порождает шаблон векторного слоя с предопределенным набором атрибутов, заданных в схеме решения задачи, который помещается в базу ГПД. Затем слой наполняется данными о пространственных координатах ОО, тем самым формиру-

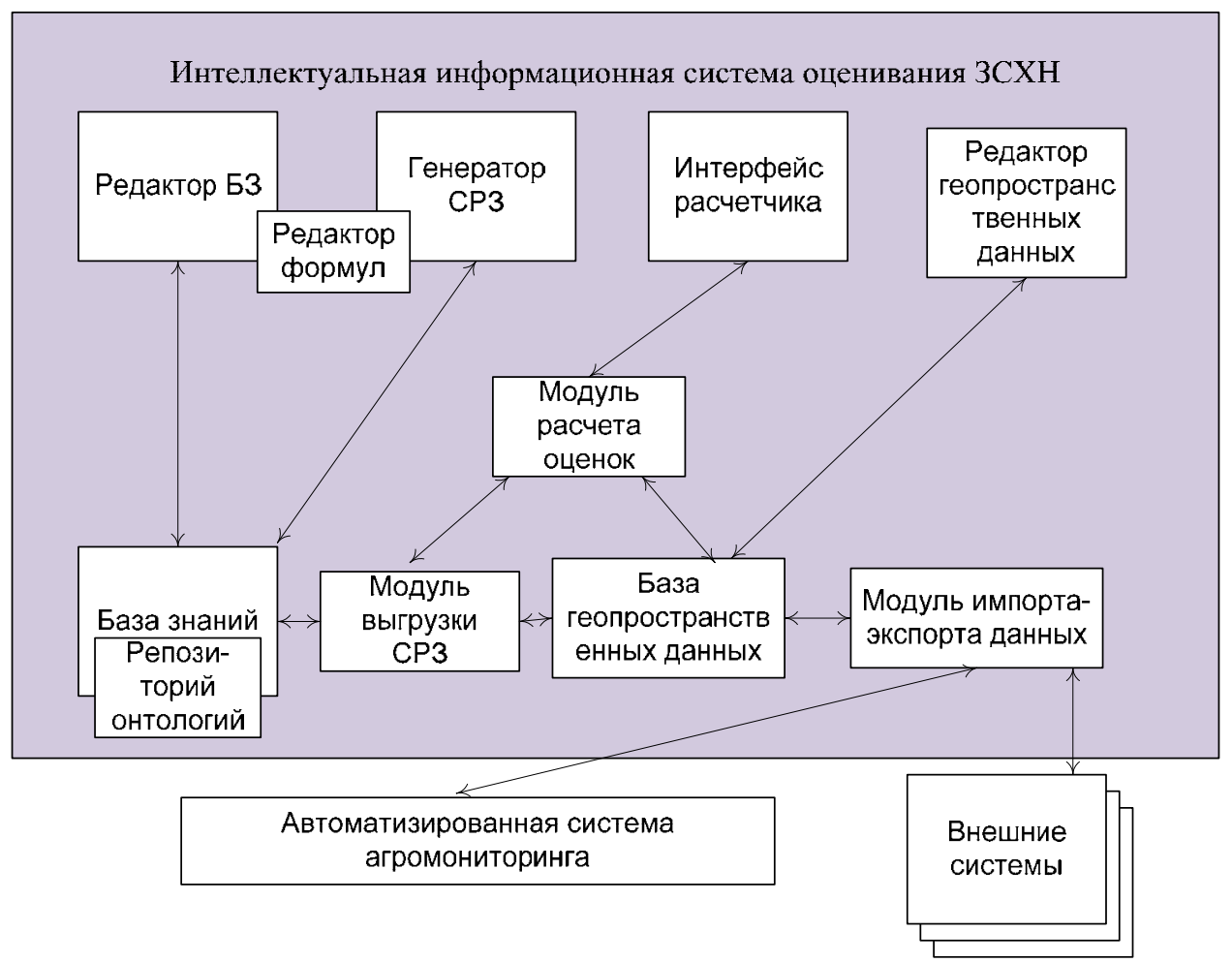

Рис. 2. Архитектура интеллектуальной системы оценивания 
ется векторное представление данных на анализируемую территорию, содержащее множество ОО как геопространственных объектов.

Атрибутивная информация содержит значения натурных параметров ОО. Поставка атрибутивной информации - ответственность модуля импорта-экспорта данных. Данный модуль взаимодействует с автоматизированной системой агромониторинга [12-13] и другими внешними системами, что позволяет получать данные на основе обработки и анализа космоснимков, наземных измерений, данных метеостанций и других источников.

Расчет промежуточных и финишных оценок производится модулем расчета оценок. Визуализация оценок осуществляется через интерфейс расчетчика, позволяющий формировать пространственное представление данных в виде векторных слоев с вычисленными атрибутами, а также отображать данные в табличной форме либо средствами деловой графики.

\section{Экспериментальная апробация}

В настоящее время создан действующий прототип системы, осуществляется отработка методик ее функционирования. В качестве инструментального обеспечения системы выступила свободно распространяемое программное обеспечение Protégé 3.5, Quantum GIS 1.8, а также авторское программное обеспечение, созданное на языке С\#, реализованное на основе среды программирования Microsoft Visual Studio 2013.

Онтология построена на базе использования концептуальной модели, рассмотренной в [8]. Верхний уровень таксономии оценивания $K$ задают следующие классы:

- Физические факторы рельефа (ФР). Эту группу образуют факторы, характеризующие ЗСХН как трехмерную поверхность в мировой системе координат, в том числе контурность, факторы формы, высота над уровнем моря, нормализованная экспозиция, угол наклона рельефа, площадь.

- Природно-климатические условия (ПК) определяют тип и основные направления ведения сельскохозяйственного производства, выбор наилучших или наиболее доходных для определенного района культур.

- Экономические факторы, обусловленные использованием земель (ЭФИЗ), определяются доходом, получаемым с этого участка, инвестициями, произведенными на данной территории.

- Свойства почвы (СП) - влияют на урожайность сельскохозяйственных культур и продуктивность земельных участков.

- Растительный покров (РП) - для земель, находящихся в сельскохозяйственном обороте, этот фактор соответствует текущей сельскохозяйственной культуре, а также определяется характеристиками засоренности.

- Эффективное расстояние до объектов инфраструктуры (ОИ): населенных пунктов, дорог, ЛЭП и других объектов, существенных для сельскохозяйственного производства.

В качестве иллюстрации функционирования системы рассмотрены схемы, полученные в ходе решения следующих задач: 1) определение оценочной степени эффективности сельскохозяйственных угодий при выращивании яровой пшеницы $\left.\left(t_{l}\right) ; 2\right)$ определение степени засоренности полей под парами $\left(t_{2}\right)$. 
При формировании схемы решения задачи $t_{l}=<K_{l}, E_{l}, M_{l}>$ построено дерево классификации признаков оценки $K_{l}$, показанное на рис. 3 (выделено синим цветом). Каждой из листовых вершин дерева установлено в соответствие функциональное свойство $m_{i} \in M_{l}$, характеризующее численное значение, единицу измерения и допустимый диапазон значений соответствующей первичной метрики, и функциональное свойство $e_{j m} \in E_{l m}$, определяющее способ вычисления оценки. Для удобства оперирования все функциональные зависимости $e_{j m}$ отображают измеримый интервал значений первичных метрик в диапазоне [0..1]. При этом используются аналитически либо таблично заданные функции преобразования. На рис. 3 схематично отображены соответствующие слоты описания данных свойств (красным цветом). Так, значение контурности поля и расстояние до центра переработки обратно пропорционально значению оценки; функции для оценки влияния содержания гумуса, кислотности почвы и площади поля заданы таблично. Множество $E_{l a}=\left\{e_{1 a}\right\}$ в описании задачи $t_{l}$ состоит из единственной вершины, инцидентной корневому узлу дерева $K_{l}$. Метрике сопоставлено взвешенное дерево, показанное на рис. 3 зеленым цветом. Вычислительное соотношение для данной метрики определено как

$$
\mathrm{O}\left(e_{1 a}\right)=\sum_{i=1}^{5} l_{i} * e_{i m}
$$

где $l_{i}-$ вес соответствующей дуги.

На основании сформированной схемы описания задачи осуществляется ранжирование выделенной совокупности земельных участков по степени пригодности для культивирования яровой пшеницы. Результирующая информация подготавливается в виде атласов земель в разрезе хозяйств, а также в виде столбчатых диаграмм, отображающих ранг того или иного поля.

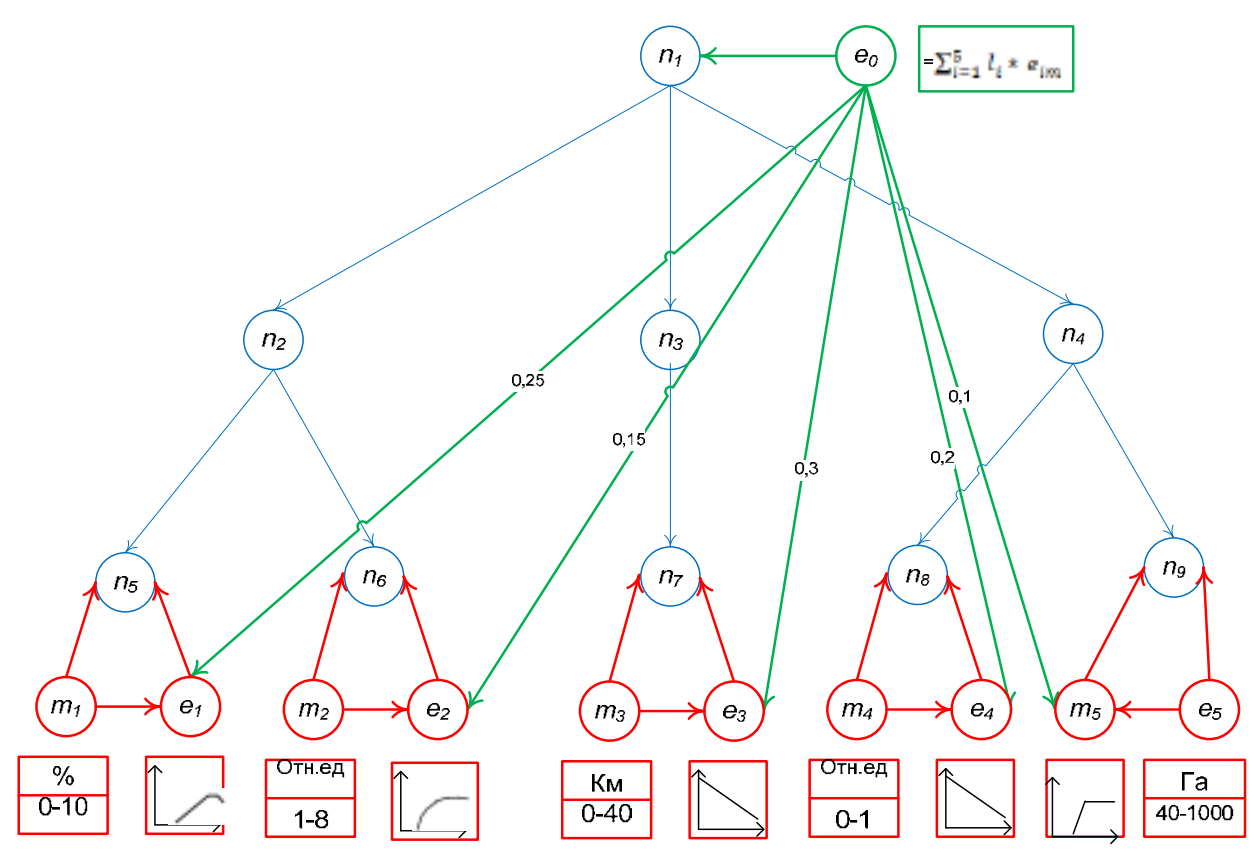

Рис. 3. Схема описания задачи $t_{1}: n_{2}-\mathrm{CП} ; n_{3}-\mathrm{OИ} ; n_{4}-\Phi Р ; n_{5}-$ содержание гумуса; $n_{6}-$ кислотность; $n_{7}$ - расстояние до центра переработки; $n_{8}-$ контурность; $n_{9}-$ площадь 


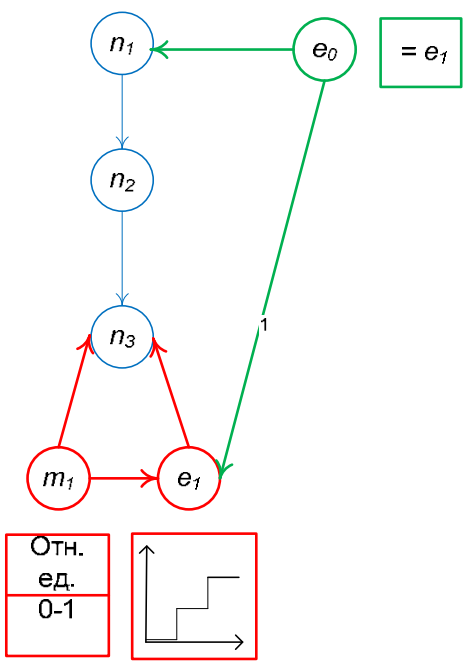

Рис. 4. Схема описания задачи $t_{2}: n_{2}-$ РП; $n_{3}-$ значение NDVI

Граф решения задачи показан на рис. 4. Схема базируется на использовании единственного параметра - индекса NDVI. Непосредственное применение схемы позволяет осуществить интегральную оценку засоренности поля под паром путем соотнесения с одним из предопределенных классов: открытая почва», «поле, требующее обработки», «поле с высокой степенью засоренности». Результирующая информация подготавливается в виде атласов земель под паром в разрезе хозяйств, а также в случае применения расчетов на протяжении полевого сезона в виде графиков изменения степени засоренности полей во времени.

\section{Заключение}

Интеллектуальная информационная система оценивания ЗСХН представляет собой инструмент, в котором содержится постоянно пополняемая и уточняемая система знаний о землях сельскохозяйственного назначения как о сложных, многофакторных объектах. Механизм уточнения и расширения базы знаний обеспечивается через систему контроля версий. Разработанная система дополняет ранее созданную авторским коллективом автоматизированную систему агромониторинга, позволяя создавать и накапливать библиотеку схем решения задач оценивания ЗСХН, включая возможность динамического наблюдения за их изменением в ходе сезона вегетации и поддержки принятия управленческих решений. Схемы решения задач создаются на базе экспертных оценок и после отладки на существенном объеме экспериментальных данных могут использоваться как объективный инструмент, масштабируясь на другие территории, обладающие сходной совокупностью природно-климатических условий. Таким образом, поддерживается четырехуровневое представление информации: 1) система знаний, описывающая предметную область оценивания ЗСХН; 2) схема задачи, описывающая конкретную постановку задачи и содержащая декларативные и процедурные средства для ее решения; 3) экземпляр решаемой задачи, локализованный на местности; 4) решение задачи, локализованное во времени (рис. 4). 


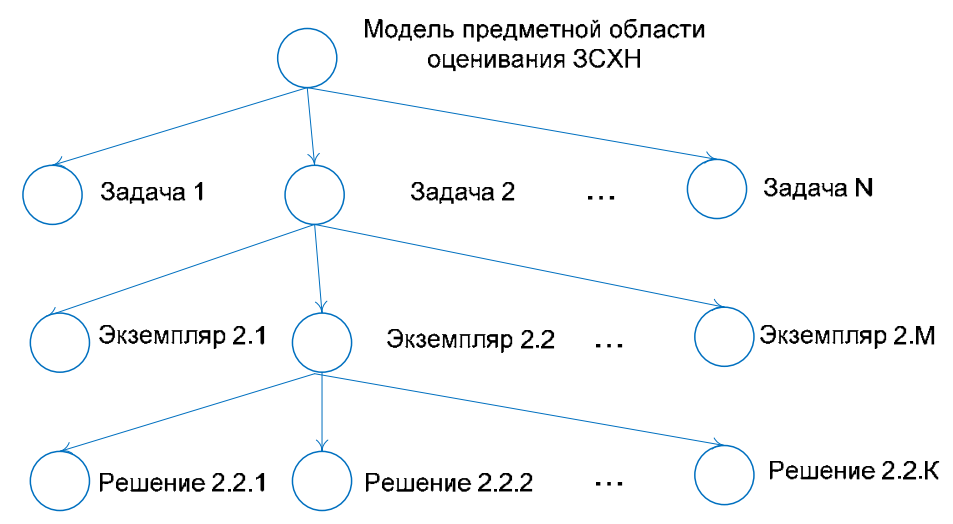

Рис. 5. Метамодель представления задач оценивания ЗСХН

Представленные в статье модели в настоящее время проходят экспериментальную апробацию при решении задач оценивания ЗСХН на территории Сухобузимского района Красноярского края в интересах администрации района и хозяйствующих субъектов.

\section{Список литературы}

[1] Мартынов К.П. Оценка земель сельскохозяйственного назначения. Электронный журнал МГУ Н.П. Огарева, 2012, 4 (18) [Martynov K. P. Assessment of the agricultural land. Electronic journal of MGU N.P. Ogareva, 2012, 4 (18) (in Russian)]

[2] Терехов А.Г., Витковская И.С., Барталева М.Ж., Спивак Л.Ф. Принципы агроландшафтного районирования пахотных земель Северного Казахстана по данным LANDSAT и MODIS. Седьмая всероссийская открытая ежегодная конферениия «Современные проблемы дистанционного зондирования Земли из космоса». Москва, ИКИ РАН, 16-20 ноября, 2009, 292-304 [Terekhov A. G., Vitkovskaya I. S., Bartaleva M. J., Spivak L. F. Principles of agrolandscape zoning of arable land in Northern Kazakhstan according LANDSAT and MODIS The seventh all-Russian open annual conference «Modern problems of Earth remote sensing from space», Moscow, IKI RAN, 16-20 November, 2009, 292-304 (in Russian)]

[3] Анохин Е.И. Понятие, принципы и методы оценки земель сельскохозяйственного назначения. Проблемы современной экономики, 3 (35), 2010 [Anokhin E. I. Concept, principles and methods of evaluation of agricultural land. J. Problems of modern Economics, 3 (35), 2010 (in Russian)]

[5] Иванов А. Л., Савин И. Ю., Егоров А. В. Методология оценки ресурсного потенциала земель России для сельскохозяйственного производства (на примере хмеля). Бюллетень Почвенного института им. В.В. Докучаева, 2014, 73, 19-53 [Ivanov A. A., Savin I. Yu., Egorov A. V. Methodology of estimation of resource potential of lands for agricultural production (for example, hops). J. Bulletin of Soil Institute. V. V. Dokuchaev, 2014, 73, 19-53 (in Russian)]

[6] Стадник А.П., Лукіша В.В. Формування критеріїв та показників для екологоекономічного оцінювання сільськогосподарського. Агроекологічний журнал, 2011, 3, 5-12 [Stadnik A. P., Luce V. V. Formation of criteria and indicators for ecological and economic assessment of agricultural. Agroecological journal, 2011, 3, 5-12 (in Ukrainian)]

$$
-1033-
$$


[7] Гуреева О.В. Особенности земель сельскохозяйственного назначения как объекта оценки. Вестник Саратовского государственного сочиально-экономического университета, 2008, 4, 78-81 [ Gureeva O. V. Peculiarities of agricultural land as the object of evaluation. Bulletin of Saratov state socio-economic University, 2008, 4, 78-81 (in Russian)]

[8] Шатрова К.В., Маглинец Ю.А. Аникьева М.А., Герасимчук М.Г. Концептуальная модель предметной области оценивания земель сельскохозяйственного назначения на основе привлечения геопространственной информации. Одиннадцатая открытая Всероссийская конференция «Современные проблемы дистанционного зондирования Земли из космоса», ИКИ РАН Москва, 2013, 65 [Shatrova K.V., Maglins Y.A., Anikeva M.A., Gerasimchuk M.G. Conceptual model of subject area evaluation of agricultural land through the involvement of the geospatial information. The eleventh all-Russian open conference «Modern problems of remote sensing of the Earth from space». IKI RAN, Moscow (in Russian)]

[9] К.А. Кузнецов и др. Онтологическое моделирование и публикащия данных об Особо Охраняемых Природных Территориях. Труды 14-й Всероссийской научной конференции «Электронные библиотеки: перспективные методы и технологии, электронные коллекции», RCDL-2012, Переславль-Залесский, Россия, 15-18 октября, 2012 [K.A. Kuznetsov, etc. Ontological modelling and publication of data on Especially Protected Natural Territories. Proceedings of the 14th all-Russian scientific conference «digital libraries: advanced methods and technologies, digital collections», RCDL-2012, Pereslavl-Zalessky, Russia, 15-18 October, 2012 (in Russian)]

[10] Мясникова, С. И. Геоонтология создания серии карт муниципальных районов. Геодезия и картография, 2012, 12, 48 (8), 41-48 [Myasnikova, S.I. Geoecologia create a series of maps of the municipal districts. Geodesy and cartography, 2012, 12, 48 (8), 41-48 (in Russian)]

[11] Шатрова К.В., Маглинец Ю.А., Цибульский Г.М. Модель представления информации о состоянии и динамике земель сельскохозяйственного назначения. Журнал Сибирского федерального университета, Техника и технологии, 2014, 7(8), 984-989 [. Shatrova K. V, Maglinets Y.A., Tsybul'skii G.M. A view model information about the state and dynamics of lands of agricultural purpose. J. Sib. Fed. Univ. Eng. technol., 2014, 7(8), 984-989 (in Russian)]

[12] Маглинец Ю.А., Мальцев Е.А., Брежнев Р.В., Соснин А.С., Цибульский Г.М., Шатрова К.В. Программно-технологическая инфраструктура представления и обработки геопространственной информации муниципального района. Современные проблемы дистанщионого зондирования Земли из космоса, 2012, 9(3), 316-323 [Magliner Y. A., Mal'tsev, E.A., Brezhnev R.V., Sosnin A. S., Tsybul'skii G.M., Shatrova K. V. Software and technological infrastructure for the submission and processing of geospatial information of the municipal area. Modern problems of remote sensing of the Earth from space, 2012, 9(3), 316-323 (in Russian)]

[13] Perfil'ev S.E., Maglinets Y.A., Tsibul'skii G.M., Mal'tsev E.A., Latyntsev A.A., Shatrova K.V. Intelligent geoinformation technology for agroecological mapping. Pattern Recognition and Image Analysis, 2013, 23 (4), 528-535 